\title{
Year of Polar Prediction - enhance observations to provide improved forecasts in polar regions
}

\author{
Kirstin Werner \\ WMO WWRP International Coordination Office for Polar Prediction, Alfred Wegener Institute Helmholtz Centre for Polar \\ and Marine Research, Bremerhaven, Germany
}

Correspondence: Kirstin Werner (kirstin.werner@awi.de)

Published: 20 May 2021

The Arctic and Antarctic are among those few places on Earth where, compared to other regions, very few data have been collected so far. But the climate and weather conditions in the polar regions are directly related to those in the mid-latitudes and thus play an important role in our daily life. With a continuously decreasing summer Arctic sea-ice cover, the socio-economic conditions in the Arctic are also expected to change. Reliable forecasts are therefore crucial to ensure safe and environmentally friendly operations in polar regions.

In 2019 and 2020, all eyes were on the MOSAiC ice drift campaign: to better understand the processes and interactions in the Arctic environment, an ice floe in the central Arctic was accompanied for an entire year by an international team of researchers, on board the German research icebreaker RV Polarstern. During MOSAiC but also in many other research projects where processes in the Arctic and Antarctic are studied, meteorologists, sea-ice physicists and modellers are currently collaborating worldwide to improve weather and sea-ice forecasts for the polar regions and beyond. With the internationally coordinated research initiative "Year of Polar Prediction", an extensive data set is being generated that enables recommendations on how observing systems in polar regions should look like in the future to reliably predict weather and sea-ice conditions for safe operations in the Arctic and Antarctic.

Through the Year of Polar Prediction, or YOPP, activities of intensive observing, modelling, prediction, verification, user engagement and education activities are coordinated across nations (Fig. 1). YOPP was initiated by the World Meteorological Organization's (WMO) World Weather Research Programme (WWRP) as the key component of the Polar Prediction Project (PPP, http://www.polarprediction. net, last access: 3 March 2021). PPP is a 10-year (20132022) endeavour with the aim of promoting cooperative international research enabling the development of improved weather and environmental prediction services for the polar regions, on timescales from hours to seasons (Jung et al., 2016). As a response to rapid polar climate change and related transformation of societal and economic activities, the Polar Prediction Project contributes to the knowledge base needed to manage the opportunities and risks that come with polar environmental transitions. By observing and modelling the Arctic and Antarctic weather and climate systems, YOPP will lead to better forecasts of weather and sea-ice conditions to improve future environmental safety at both poles.

Germany is hosting the International Coordination Office for Polar Prediction at the Alfred Wegener Institute (AWI) Helmholtz Centre for Polar and Marine Research, Bremerhaven, Germany.

\section{Special observing periods}

The core phase of the Year of Polar Prediction (YOPP) was launched in mid-2017 as a coordinated 2-year period of enhanced observing, modelling and verification efforts. Since then, scientists and operational forecasting centres worldwide have closely worked together to observe, model, and hereby improve predictions of the Arctic and Antarctic weather and climate systems. During three special observing periods in 2018-2019, the number of routine observations such as radiosonde launches and buoy deployments was increased in the Arctic and in the Antarctic, aiming to close gaps in atmospheric and sea-ice observations and to enable 


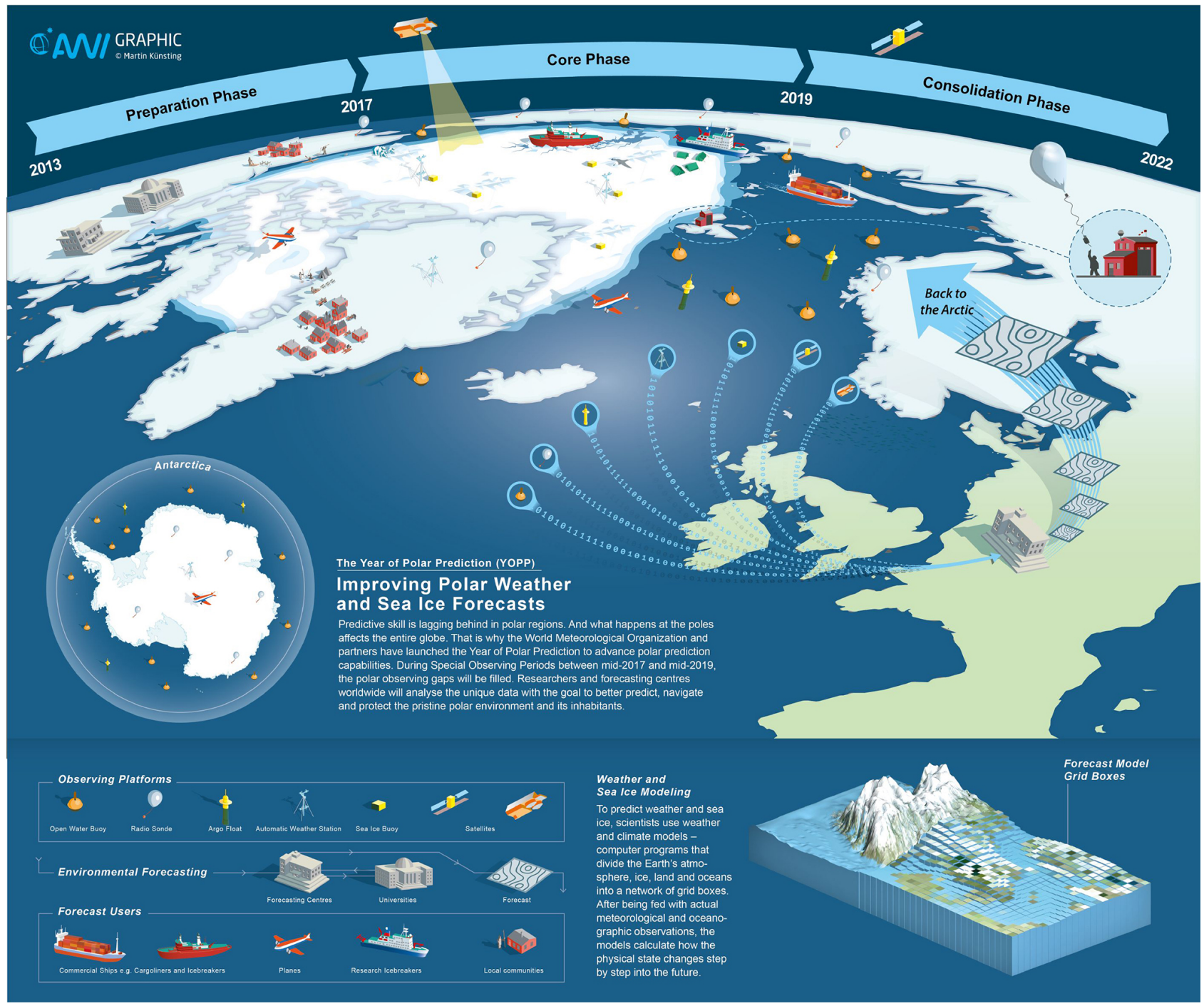

Figure 1. Overview of the Year of Polar Prediction (infographic: Martin Künsting/Alfred Wegener Institute).

significant progress in environmental prediction capabilities for the polar regions and beyond (Fig. 2).

\section{Targeted observations}

A third Arctic observational period was aligned with the MOSAiC drift in spring 2020. This campaign focused on improving observational coverage during an episode of strong interactions between the Arctic and mid-latitudes, i.e. warm air intrusions associated with the mid-latitudes driving Arctic weather and climate. During the Targeted Observing Period that happened around two warm air intrusion events on 16 and 19 April 2020, additional radiosondes were launched from different stations situated along the intrusions. Another targeted observing period is currently planned for winter 2022 in and around Antarctica. 


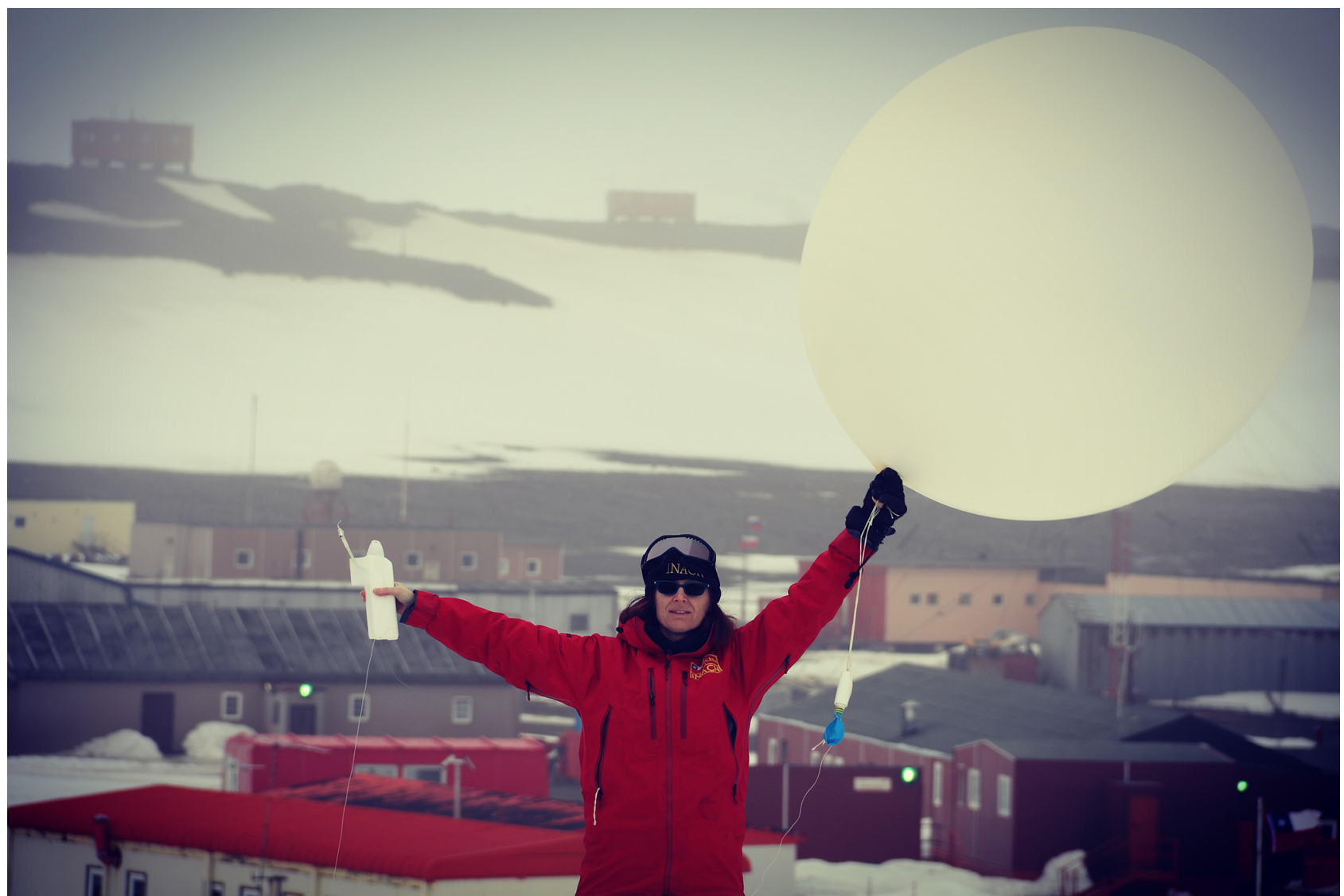

Figure 2. Penny Rowe from the University of Santiago, Chile, launches a radiosonde from the Antarctic Chilean Research Station Escudero. Radiosondes were launched twice daily during the Antarctic Special Observing Period as part of Chile's YOPP-endorsed project "Characterization of the Antarctic Atmosphere and Low Clouds" (CAALC) - a collaboration with the nearby South Korean King Sejong Station and the Korea Polar Research Institute, KOPRI (photo: Nicolas Dettling).

\section{Process-based model evaluation}

In mid-2019, YOPP moved into its consolidation phase, which will be key for the success of the initiative. Central activities and projects such as the YOPPsiteMIP initiative significantly contribute to improving forecasts of polar weather and sea-ice conditions. YOPPsiteMIP stands for "Year of Polar Prediction site Model Inter-comparison Project". It is a coordinated process-based model evaluation at selected Arctic and Antarctic supersites. The MOSAiC central observatory and its surrounding distributed network of instruments play a vital role here as one of the Arctic YOPP supersites. Together with data from other supersites, MOSAiC observational data will be used within YOPPsiteMIP to standardise measurement procedures in order to compare instrumental observations with model data output at high frequency. This will enable multi-model and multi-site verification and process evaluation until the end of the Polar Prediction Project in 2022, and beyond. A unique open data set of paired model output and observations is going to be generated. It extends by far the traditional synoptic surface and upper-air observations and offers the opportunity for deepening our understanding of the physical processes governing the polar environment's weather and climate.

\section{YOPP Data Portal}

Amongst many other YOPP-related data sets, model output data from YOPPsiteMIP are already available for the first Arctic YOPP Special Observing Period in the YOPP Data Portal (https://yopp.met.no/, last access: 3 March 2021). The majority of data collected during YOPP-endorsed observational campaigns as well as by modelling and verification efforts will be stored at national data centres and portals. The YOPP Data Portal provides the corresponding metadata linking to the respective data sets generated during the Year of Polar Prediction. The YOPP Data Portal is developed by the Norwegian Meteorological Institute (MET Norway) and in close collaboration with data centres that provide sufficient interoperability and work with the socalled FAIR Guiding Principles (Wilkinson et al., 2016). 
The Polar Prediction Project will come to an end in 2022. With YOPP, MOSAiC and many other projects, scientists, experts at operational forecasting centres and various stakeholder groups operating in polar regions will have collected a huge number of data that will be available to jointly work on advancing forecast capabilities in the Arctic and Antarctic - with the ultimate goal of ensuring a safe, respectful and trustworthy utilisation of what the polar regions offer to humankind also in the future.

Data availability. Further information on the Polar Prediction Project can be found at http://www.polarprediction.net (last access: 3 March 2021). The YOPP Data Portal at http://yopp.met.no (last access: 3 March 2021) provides metadata and links to respective data sets generated in the framework of the Polar Prediction Project.

Competing interests. The author declares that there is no conflict of interest.

Acknowledgements. This is a contribution to the Year of Polar Prediction (YOPP), a flagship activity of the Polar Prediction Project (PPP), initiated by the World Weather Research Programme (WWRP) of the World Meteorological Organization (WMO). We acknowledge the WMO WWRP for its role in coordinating this international research activity.

Review statement. This paper was edited by Bernhard Diekmann.

\section{References}

Jung, T., Gordon, N. D., Bauer, P., Bromwich, D. H., Chevallier, M., Day, J. J., Dawson, J., Doblas-Reyes, F., Fairall, C., Goessling, H. F., Holland, M., Inoue, J., Iversen, T., Klebe, S., Lemke, P., Losch, M., Makshtas, A., Mills, B., Nurmi, P., Perovich, D., Reid, P., Renfrew, I. A., Smith, G., Svensson, G., Tolstykh, M., and Yang, Q.: Advancing Polar Prediction Capabilities on Daily to Seasonal Time Scales, B. Am. Meteorol. Soc., 97, 1631-1647, 2016.
Wilkinson, M. D., Dumontier, M., Aalbersberg, I. J., Appleton, G., Axton, M., Baak, A., Blomberg, N., Boiten, J.-W., da Silva Santos, L. B., Bourne, P. E., Bouwman, J., Brookes, A. J., Clark, T., Crosas, M., Dillo, I., Dumon, O., Edmunds, S., Evelo, C. T., Finkers, R., Gonzalez-Beltran, A., Gray, A. J. G., Groth, P., Goble, C., Grethe, J. S., Heringa, J., 't Hoen, P. A. C., Kuhn, T., Kok, R., Kok, J., Lusher, S. J., Martone, M. E., Mons, A., Packer, A. L., Persson, B., Rocca-Serra, P., Roos, M., van Schaik, R., Sansone, S.-A., Schultes, E., Sengstag, T., Slater, T., Strawn, G., Swertz, M. A., Thompson, M., van der Lei, J., van Mulligen, E., Velterop, J., Waagmeester, A., Wittenburg, P., Wolstencroft, K., Zhao, J., and Mons, B.: The FAIR Guiding Principles for scientific data management and stewardship, Sci. Data, 3, 160018, https://doi.org/10.1038/sdata.2016.18, 2016. 